\title{
Palaeoclimatic events, dispersal and migratory losses along the Afro-European axis as drivers of biogeographic distribution in Sylvia warblers
}

\author{
Gary Voelker ${ }^{*}$ and Jessica E Light
}

\begin{abstract}
Background: The Old World warbler genus Sylvia has been used extensively as a model system in a variety of ecological, genetic, and morphological studies. The genus is comprised of about 25 species, and $70 \%$ of these species have distributions at or near the Mediterranean Sea. This distribution pattern suggests a possible role for the Messinian Salinity Crisis (from 5.96-5.33 Ma) as a driving force in lineage diversification. Other species distributions suggest that Late Miocene to Pliocene Afro-tropical forest dynamics have also been important in the evolution of Sylvia lineages. Using a molecular phylogenetic hypothesis and other methods, we seek to develop a biogeographic hypothesis for Sylvia and to explicitly assess the roles of these climate-driven events.

Results: We present the first strongly supported molecular phylogeny for Sylvia. With one exception, species fall into one of three strongly supported clades: one small clade of species distributed mainly in Africa and Europe, one large clade of species distributed mainly in Africa and Asia, and another large clade with primarily a circumMediterranean distribution. Asia is reconstructed as the ancestral area for Sylvia. Long-distance migration is reconstructed as the ancestral character state for the genus, and sedentary behavior subsequently evolved seven times.

Conclusion: Molecular clock calibration suggests that Sylvia arose in the early Miocene and diverged into three main clades by $12.6 \mathrm{Ma}$. Divergence estimates indicate that the Messinian Salinity Crisis had a minor impact on Sylvia. Instead, over-water dispersals, repeated loss of long-distance migration, and palaeo-climatic events in Africa played primary roles in Sylvia divergence and distribution.
\end{abstract}

\section{Background}

The avian genus Sylvia is an Old World warbler lineage comprising roughly 25 species, to include species which were until recently placed in other genera [[1-3]; Parisoma, Pseudalcippe, and Horizhorinus, respectively]. The genus as a whole is distributed from central Eurasia to the tip of South Africa, and about 70\% of Sylvia species have ranges that abut, or very nearly abut, the Mediterranean Sea. Individual species' ranges vary from widespread inter-continental migrants such as the Greater Whitethroat (Sylvia communis) to highly restricted island endemics in the Mediterranean Sea and Gulf of Guinea to include the Balearic Warbler (Sylvia balearica) and Dohrn's Thrush-babbler [Sylvia dohrni; [3,4]].

\footnotetext{
* Correspondence: gvoelker@tamu.edu

Department of Wildlife and Fisheries Sciences and Texas Cooperative Wildlife Collections, Texas A\&M University, College Station, TX 77843, USA
}

Because Sylvia species are highly variable in distribution, range sizes and migratory behavior, they have been used extensively as a model system in a variety of studies including morphological evolution, the genetics of migration, the effects of climate change on migration, and the evolution of range size [e.g., [2,5-10]]. Some of these studies have relied on molecular phylogenies as the basis for understanding evolutionary patterns in the genus [e.g., $[2,9]]$. The phylogenies used, however, have generally been based on neighbor-joining algorithms and the resulting phylogenetic hypotheses have lacked support for most relationships. The only study to use molecular tools to investigate the historical biogeography of the genus relied on DNA-DNA hybridization of 20 Sylvia species; results were such that only a few broad-brush biogeographic questions could be addressed [1].

\section{C) Biomed Central}


Overall then, a well-resolved phylogeny of Sylvia is still lacking. Thus, uncertainty remains when attempting to explain evolutionary patterns within Sylvia, and most questions relating to the historical biogeography of the genus remain unaddressed, including when and how most lineage divergences occurred. For example, the high percentage of Sylvia species distributed on Mediterranean islands or around the margins of the sea in Europe and North Africa (Figure 1) suggest that overwater dispersal or vicariance related to sea-level change might have been important factors in lineage diversification. Indeed, the Miocene-Pliocene boundary, at $~ 5.3$ million years ago (Ma), is defined by environmental changes associated with the end of the Messinian Salinity Crisis [MSC; [11,12]], specifically the re-filling of the Mediterranean Sea following complete desiccation.

Although lasting for a rather short period of evolutionary time [from 5.96-5.33 Ma; [13]], the desiccation of the Mediterranean would have allowed land-based colonization routes for population expansion to islands (e.g., Sardinia) and between Europe and Africa. Subsequent re-filling of the Mediterranean at the end of the MSC would have created a vicariant barrier to further land-based colonization, thus driving lineage diversification between (now isolated) populations. This same mechanism could explain the trans-Mediterranean distribution of a number of Sylvia species [4]. Alternatively, lineages could have diverged while the Mediterranean was filled, before or after the MSC, suggesting that over-water dispersal might have been important in the evolution of Sylvia, as has been shown in other avian lineages [e.g., $[14,15]]$. Molecular clock dates are key to being able to discriminate between vicariance and dispersal hypotheses [e.g., [16]]. Similar questions relating to the possible vicariant impact of the MSC on lineage divergence, or the Mediterranean as a dispersal barrier to island or intercontinental colonization have been addressed for a variety of animal taxa to include butterflies [e.g., [17]], fish [e.g., [18,19]], mammals [e.g., $[20,21]]$, and reptiles and amphibians [e.g., [22-24]].

Away from the Mediterranean, distributions of other Sylvia species suggest that both Asian-African and Northeastern (e.g., Ethiopia)-Southern African interchanges were important in the evolution of the genus (Figure 1). There are good palaeo-climatic and palaeoecological records of African habitats extending back to the late Miocene, and major shifts in climate had a significant impact on Afrotropical forest expansion and contraction. These forest shifts have been shown to have been important in the evolution of a variety of vertebrate lineages, serving as vicariance barriers for species breeding in arid or montane regions, and as dispersal corridors from Asia for forest adapted species [e.g., $[16,25-31]]$.
Our aims in this paper were to develop a well-resolved molecular phylogenetic hypothesis of Sylvia warblers, and to use this phylogeny in conjunction with molecular clock calibrations to reconstruct the historical biogeography of the genus. Based on Sylvia distributions, we hypothesize that the Messinian Salinity Crisis will have played a major role in lineage diversification around the Mediterranean Sea. Because most African breeding Sylvia species do not breed in tropical forests, we further hypothesize that expansion and contraction of Afrotropical forests will have played a role in lineage diversification between northern and southern African species. In assessing these hypotheses, we also assess the possible role that changes in migratory habit might have played in the evolution of Sylvia distributions.

\section{Methods}

\section{Molecular methods and phylogenetic analysis}

We included all species of Sylvia following Sibley and Monroe [[32]; Table 1]. We also included several species previously recognized as races of other Sylvia taxa, as well as taxa that have more recently been shown to be part of the genus [e.g., Parisoma, Pseudalcippe, and Horizhorinus; [1-3]]. Sylvia leucomelaena is represented by cytochrome $b$ data obtained from GenBank. As outgroups, we included individuals from closely related (Chamaea, Paradoxornis) and more distant genera [Turdoides, Zosterops; [33]]. We did not recognize Sylvia moltonii here, although moltonii has been suggested as specifically distinct from cantillans because of its genetic distance relative to other cantillans races [4-5\%; [34]]. Comparing a moltonii cytochrome $b$ sequence (GenBank EU760693) to our samples of cantillans (one S. c. cantillans from Senegal and one S. c. albistriata from Greece) we find a $4.5 \%$ difference. But more importantly, we find a far higher divergence between our two samples of cantillans $(3.6 \%)$ than that reported in the literature [0.35\%; [34]]. We agree with Brambilla et al. [34] that regardless of taxonomic rank, moltonii is sister to other cantillans races (analysis not shown) and also agree that many questions in the cantillans complex remain unsolved. In the current study, the distribution of moltonii is therefore reflected in our scoring for cantillans.

We obtained extracted DNA for a number of species (those preceded by a "B" in Table 1), which have been previously used in assessments of Sylvia relationships [e. g., $[2,9]]$. For new samples, whole genomic DNA was extracted from tissue using the DNeasy tissue extraction kit (Qiagen). For all samples, we used the polymerase chain reaction (PCR) to amplify the mitochondrial NADH dehydrogenase subunit 2 (ND2) and cytochrome- $b$ (cyt- $b$ ) genes using published primers and protocols [35]. Automated sequencing was performed 


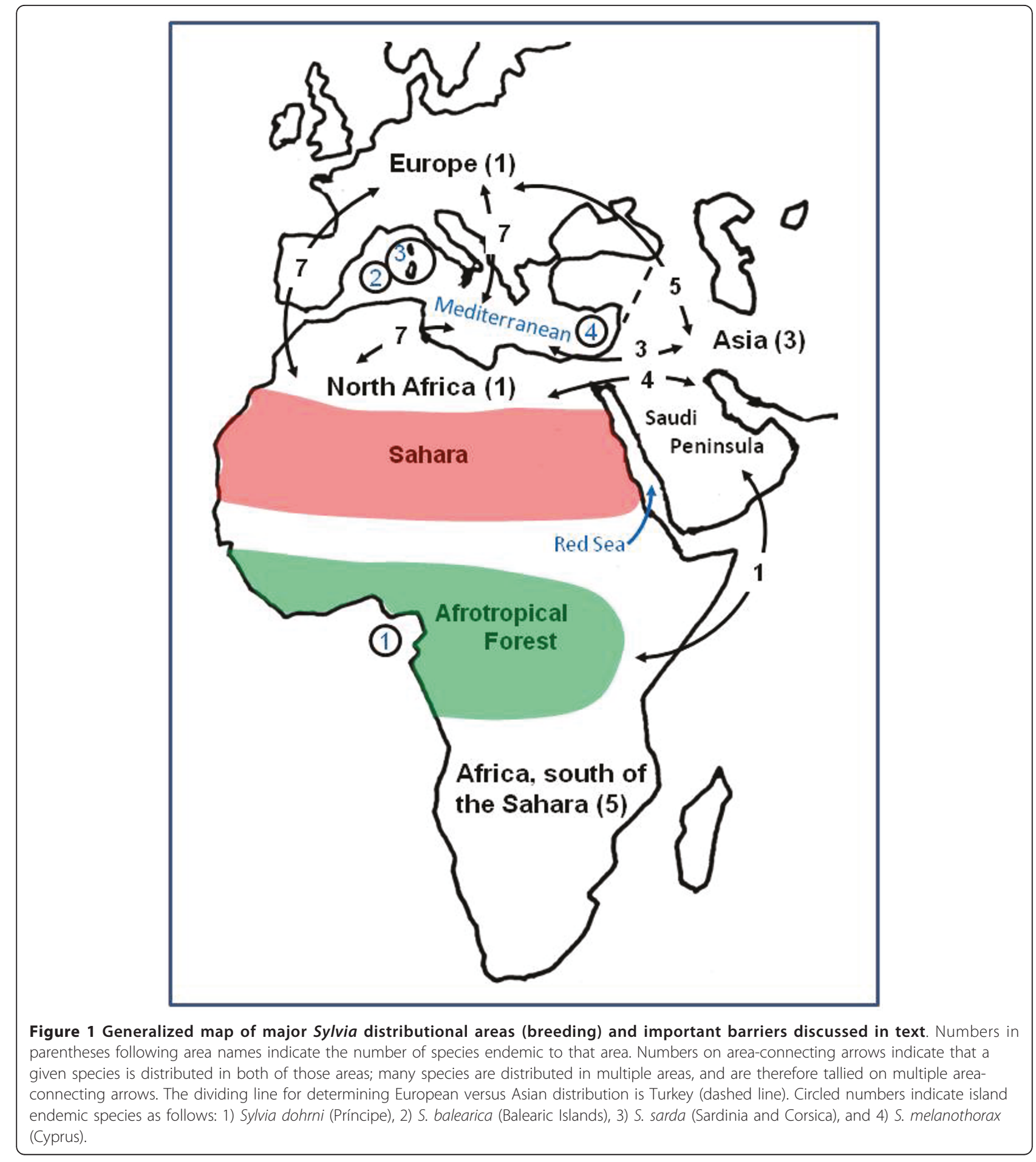

using BigDye (Applied Biosystems) and products were run out on an $A B I 377$ sequencer.

We used SEQUENCHER, version 4.5 (Gene Codes) to align ND2 and cyt- $b$ sequences for each sample. To ensure the accuracy of amplification of the ND2 and cyt $-b$ genes, we sequenced both heavy and light strands, and verified that sequence data were protein-coding. Sequences have been deposited on GenBank under accession numbers JF502273-JF502352 and alignments are available on TreeBase (submission S11495).

Combined sequence data were analyzed under three different weighting schemes using Bayesian methods. In 
Table 1 Species, museum voucher specimen or tissue number, and country of collection for specimens examined

\begin{tabular}{|c|c|c|}
\hline Species & $\begin{array}{l}\text { Sample } \\
\text { source }^{a}\end{array}$ & Country of collection \\
\hline \multicolumn{3}{|l|}{ Sylvia } \\
\hline buryi & В 0117 & Saudi Arabia \\
\hline lugens & ZMUC 120221 & Tanzania \\
\hline boehmi 1 & K 35973 & Kenya \\
\hline 2 & K 29774 & Kenya \\
\hline layardi 1 & В 0120 & South Africa \\
\hline 2 & MBM 11954 & South Africa \\
\hline subcaeruleum 1 & MBM 11953 & South Africa \\
\hline 2 & B 0865 & South Africa \\
\hline atricapilla 1 & MSUZM 119073 & $\begin{array}{l}\text { Russia: Avtonomna Respublika } \\
\text { Krym }\end{array}$ \\
\hline 2 & USNM 640935 & Russia: Krasnodarskiy Kray \\
\hline 3 & USNM 640863 & Greece: Macedonia \\
\hline 4 & YPM 101281 & Greece: Crete \\
\hline borin 1 & MBM 11430 & Malawi \\
\hline 2 & $\begin{array}{l}\text { MSUZM-MVK } \\
26\end{array}$ & Russia: Vologodskaya Oblast \\
\hline communis 1 & B 0116 & Germany \\
\hline 2 & BMNH 44368 & Russia: Krasnodarskiy Kray \\
\hline 3 & YPM 101274 & Greece: Crete \\
\hline 4 & USNM 640581 & Russia: Chitinskaya Oblast \\
\hline curruca 1 & USNM 640015 & Russia: Chitinskaya Oblast \\
\hline 2 & MSUZM 119078 & Russia: Avto. Respublika Krym \\
\hline 3 & B 0073 & Israel \\
\hline nana 1 & В 0788 & Israel \\
\hline 2 & UWBM 57866 & Mongolia \\
\hline nisoria 1 & USNM 639640 & Moldova \\
\hline 2 & $\begin{array}{l}\text { MSUZM-MVK } \\
24\end{array}$ & Russia: Vologodskaya Oblast \\
\hline hortensis & USNM 640748 & Greece: Aegean \\
\hline crassirostris & В 0099 & Israel \\
\hline leucomelaena & GenBank & AJ534533 \\
\hline rueppelli 1 & B 0776 & Israel \\
\hline 2 & YPM 101293 & Greece: Crete \\
\hline melanocephala & YPM 101408 & Greece: Crete \\
\hline 2 & B 0765 & Senegal \\
\hline melanothorax & В 0787 & Israel \\
\hline mystacea & USNM 639611 & Iran \\
\hline cantillans 1 & USNM 640818 & Greece: Aegean \\
\hline 2 & B 0065 & Senegal \\
\hline conspicillata & B 0764 & Israel \\
\hline deserticola & B 0881 & Morocco \\
\hline undata & В 0775 & Spain \\
\hline sarda & В 0795 & Corsica \\
\hline balearica & B 0128 & Mallorca: Cabrera Island \\
\hline dohrni & MM 1 & Principe Island \\
\hline abyssinicus & GenBank & EU652717, AJ534548 \\
\hline Chamaea fasciata & GenBank & DQ861975, AF484842 \\
\hline
\end{tabular}

Table 1 Species, museum voucher specimen or tissue number, and country of collection for specimens examined (Continued)

\begin{tabular}{lll}
\hline $\begin{array}{l}\text { Paradoxornis } \\
\text { nipalensis }\end{array}$ & GenBank & FJ357998, AF484875 \\
$\begin{array}{l}\text { Turdoides bicolor } \\
\text { Zosterops pallidus }\end{array}$ & MBM 8230 & AY329444, AY329481 \\
\hline
\end{tabular}

${ }^{\mathrm{a}} \mathrm{B}$, collection of A. Helbig; $\mathrm{K}$, collection of $\mathrm{K}$. Böhning-Gaese; BMNH, Bell Museum of Natural History; MBM, Marjorie Barrick Museum of Natural History; MM, collection of M. Melo; MSUZM, Moscow State University Zoological Museum; SDSU, San Diego State University; USNM, U.S. National Museum; UWBM, University of Washington Burke Museum; ZMUC, YPM, Yale Peabody Museum; Zoologisk Museum University of Copenhagen.

our first weighting scheme (two partitions) the ND2 and $c y t-b$ genes were unlinked and allowed to estimate gene appropriate GTR $+\mathrm{I}+\Gamma$ parameters. In the second (four partitions), first and second codons were linked for ND2, linked for cyt- $b$ gene, and third codon positions for each gene were treated as independent partitions. In the third scheme (six partitions), each codon position was unlinked. We used MrModelTest [36] to determine appropriate models of nucleotide substitution and to choose best-fit model of sequence evolution for each partition.

For each weighting scheme, we used MRBAYES [37] to initiate four runs of four Markov-chain Monte Carlo (MCMC) chains of 2 million generations each from a random starting tree, sampling every 100 generations. Each run resulted in 20,000 trees and converged on the same topology. The first 50,000 generations (5000 trees) from each analysis were removed as our "burn-in", and the remaining 60,000 trees were used to create a majority rule consensus tree. A longer run of 4 million generations did not affect tree topology or posterior probability values. Bayes factors were computed using the harmonic means of the likelihoods calculated from the sump command within MRBAYES. A difference of 2 ln Bayes factor $>10$ was used as the minimum value to discriminate between analysis schemes $[38,39]$, and the six partition weighting scheme was identified as the best fit to the data.

In addition to assessing nodal support via posterior probabilities derived from MRBAYES, we also assessed nodal support via 1000 bootstrap pseudo-replicates in Randomized Axelerated Maximum Likelihood Computing [RAxML-VI-Abe; [40]], using GTR + I + $\Gamma$ parameters for each codon position.

\section{Molecular clock}

We used the program BEAST v1.6.1 to estimate divergence times within Sylvia [41,42]. Prior to these analyses, the data set was pruned to include only one representative of each species in most cases; two representatives per species were included when high levels of genetic 
differentiation were present within a species (e.g., curruca). Because of the absence of an acceptable fossil calibration point within Sylvia, we employed a lineage substitution rate of 0.0105 per site/million years. This mean substitution rate translates to $2.1 \%$ per million years, and is generally accepted as applicable to the cyt- $b$ gene in songbirds [e.g., [43]]. We employed a normal distribution for this prior and assigned a standard deviation of 0.0013 , which encompasses a slower (1.6\%) and faster (2.53\%) estimate calculated for songbird cyt- $b$ substitution rates in other studies $[44,45]$. Before estimating divergence times, likelihood ratio tests were performed using PAUP* 4.0b10s [46] to determine if the cyt- $b$ sequence data departed significantly from clocklike behavior. These analyses revealed the Sylvia cyt-b data are not clocklike, therefore our substitution rate was enforced using a relaxed, uncorrelated lognormal clock. In BEAST, a Yule process speciation prior and an uncorrelated lognormal model of rate variation were implemented in each analysis. The best-fit model of nucleotide substitution for the entire cyt- $b$ gene was selected as described above $(\mathrm{GTR}+\mathrm{I}+\mathrm{G})$. Two separate MCMC analyses were run for 10,000,000 generations with parameters sampled every 1000 steps, and a 10\% burn-in. Independent runs were combined using LogCombiner v.1.6.1 [42]. Tracer v.1.5 [47] was used to measure the effective sample size of each parameter (all resulting effective sample sizes exceeded 200) and calculate the mean and upper and lower bounds of the $95 \%$ highest posterior density interval (95\% HPD) for divergence times. Tree topologies were assessed using TreeAnnotator v.1.6.1 [42] and FigTree v.1.3.1 [48]. Analyses performed separating codon positions into individual partitions resulted in failure of the BEAST run to converge after 100,000,000 generations in the MCMC analyses.

\section{Ancestral Areas}

For biogeographic analysis, we used both DispersalVicariance Analysis [DIVA; [49]] and likelihood analysis of geographic range evolution (dispersal-extinction cladogenesis) implemented in LaGrange v. 2.0.1 [50]. In DIVA we used the "maxareas" option to limit the range of ancestral distributions to no more than two areas. In LaGrange we used the default number of ancestral distributions which is based on the overall number of area distributions. In both analyses, we used range maps [4] to code each species as present or absent in each of five areas: Africa south of the Sahara, North Africa, Mediterranean Islands, Europe, and Asia (which was broadly defined to include the Saudi Peninsula and the Middle East; Figure 1). The dividing point between Europe and Asia was Turkey (Figure 1). In LaGrange, ancestral areas were reconstructed by performing likelihood optimizations on the BEAST maximum clade credibility tree.
We ran two sets of analyses based on the above distributions. In the first, we included island distributions for those species that also had broad continental distributions; this led to a result of Mediterranean Islands being the ancestral area at most nodes in one major clade (see below). In the second analyses, we only scored a species as having an island distribution if it was an island endemic (balearica, sarda, melanothorax) or nearly endemic (rueppelli).

\section{Migration}

We classified each species as having migratory or sedentary behavior, following the designations used by Böhning-Gaese et al. [2]. We used MacClade [51] to trace and reconstruct ancestral character states across the phylogeny.

\section{Results}

\section{Sylvia phylogeny}

We analyzed 1040 basepairs (bp) from the ND2 gene, and $999 \mathrm{bp}$ from the cyt- $b$ gene, for a total of $2039 \mathrm{bp}$. Given the lack of alignment problems (no insertions or deletions) and stop codons, the genes amplified were most likely of mitochondrial origin. Within our core clade of Sylvia (Figure 2) there were 546 variable sites (434 parsimony informative) in the ND2 data and 398 variable sites (341 parsimony informative) in the cyt- $b$ data. Mean nucleotide frequency for ND2 was $\mathrm{A}=$ $31.2 \%, \mathrm{C}=35.7 \%, \mathrm{G}=9.5 \%, \mathrm{~T}=23.6 \%$, with generally similar values for cyt- $b(26.4 \%, 35.2 \%, 13.6 \%, 24.8 \%)$.

Maximum likelihood (ML) and Bayesian analyses identified a monophyletic Sylvia relative to the outgroup taxa (Figure 2). Both Bayesian posterior probabilities (PP) and ML bootstrap support (BS) values indicated very strong support for most relationships in Sylvia. Just four nodes were supported at less than $0.95 \mathrm{PP}$, and only two nodes were supported at less than $75 \%$ BS (Figure 2).

Three major clades are evident in the phylogeny (Figure 2). Clade 1 comprises a group of four species, two of which are endemic to Africa (dohrni and abysinnicus) and two that breed largely in Europe or Eurasia and winter largely in Africa (borin and atricapilla). Voelker et al. [3] previously suggested that dohrni belonged in this clade as sister to abysinnicus, rather than in the monotypic genus Horizorhinus, and our results here confirm this.

The next divergence places Sylvia nana basal to the two remaining major clades (Clades 2 and 3), although the sister relationship between these major clades is not well supported by either PP or BS measures (Figure 2). Clade 2 comprises a group of 11 species with breeding distributions around the Mediterranean (including southwestern Asia), and includes three Mediterranean island endemics (balearica, sarda, and melanothorax). 


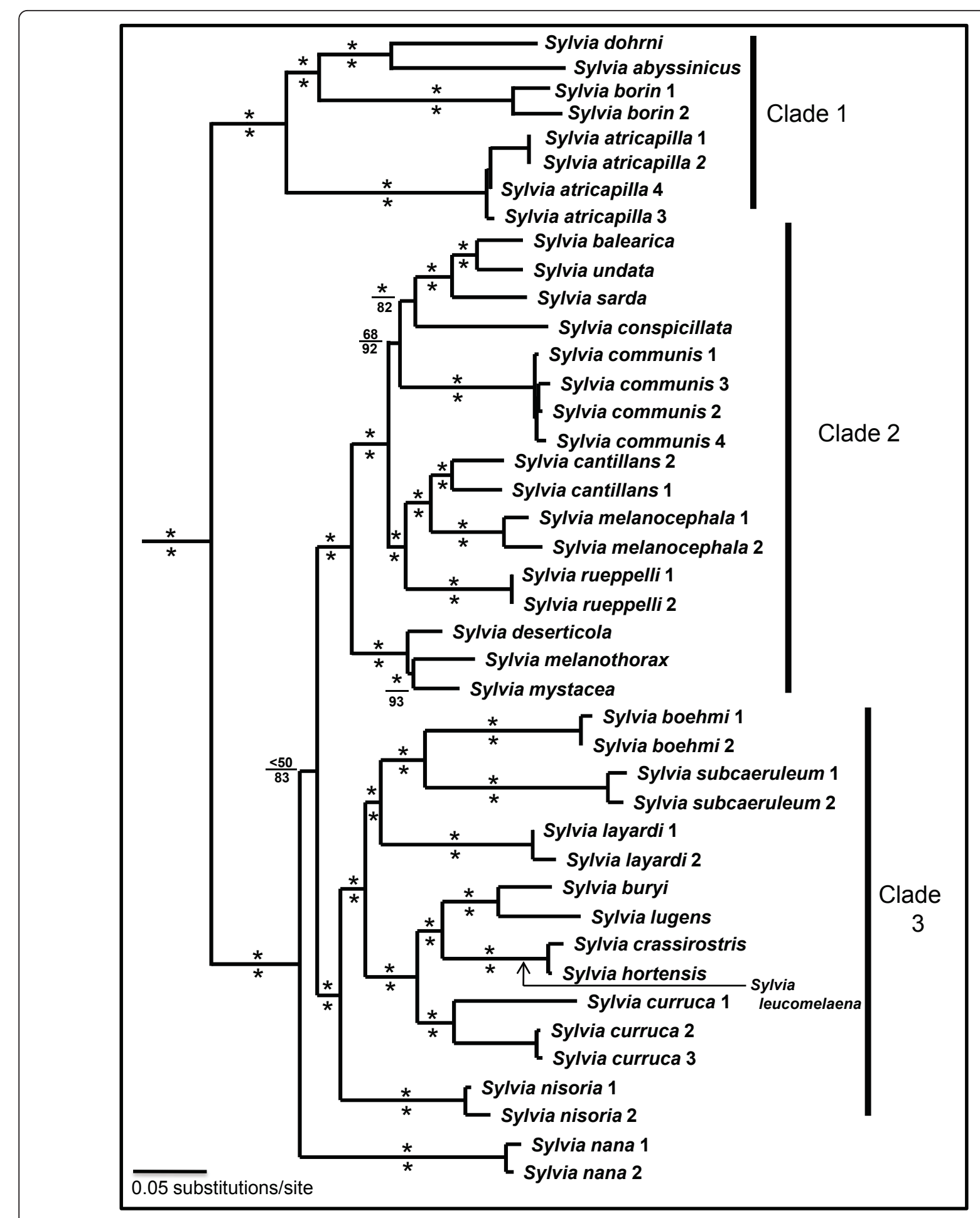

Figure 2 Phylogeny of Sylvia warblers, based on maximum likelihood and Bayesian analyses of mitochondrial cyt- $b$ and ND2 data. Values above nodes are maximum likelihood bootstrap support values; asterisks denote support values $\geq 75$. Values below nodes are Bayesian posterior probabilities; asterisks denote probabilities $\geq 95$. The phylogenetic position of Sylvia leucomelaena is based on cyt- $b$ data only. 
Nodal support values for most relationships in this clade are high under one or both measures of support.

Clade 3 is comprised of species that breed around the Mediterranean (including southwestern Asia), as well as four African endemics (boehmi, subcaeruleum, layardi, and lugens). Ten, and perhaps 11 species are included in this clade, depending on how curruca 1 is defined (Figure 2). The relatively deep divergence between our curruca samples ( $8 \%$ uncorrected cyt- $b$ data) suggests that two species could be included here. Based on phenotypic and molecular data two species, minula and althaea, have been recognized as species distinct from curruca. However the systematics and species status of minula and althaea remains controversial [4]. Our curruca 1 is from the defined range of "minula" but we did not have a sample from the range of althaea (2 and 3 are from the defined range of curruca). Regardless, as minula is a Eurasian breeding migrant its recognition here would not influence our additional analyses, and we keep this sample identified as curruca. As with the other major clades, relationships in this third clade are strongly supported.

\section{Biogeographic history and divergence dating}

Ancestral area reconstructions in both DIVA and LaGrange identified Asia, or Asia + Europe as probable area(s) for the origin of Sylvia (Figure 3). Given the position of Sylvia near or inside babblers (Timaliidae) in broader phylogenies [e.g., [33,52]], Asia is the most likely ancestral area. Overall, 24 dispersals were inferred by DIVA to explain current distributions across Sylvia.

Molecular clock calibration sets the origin of Sylvia to $\sim 20 \mathrm{Ma}$, with diversification of extant lineages beginning at 19.4 Ma (Figure 4). Speciation of extant species within Clade 1 is dated to $14.5 \mathrm{Ma}$ (Figure 4) and Europe is reconstructed as the most likely ancestral area for this clade (Figure 3). Following the divergences of atricapilla and borin, a sub-Saharan distribution was established (Figure 3), with a subsequent divergence between dohrni (Gulf of Guinea Island endemic) and abysinnicus (broad Afro-tropical distribution).

Sylvia nana diverged from the remaining Sylvia 14.5 $\mathrm{Ma}$, and Clades 2 and 3 diverged from one another 12.6 Ma (Figure 4). Asia is reconstructed as the ancestral area for these clades (Figure 3). Within Clade 3, four Asian to African movements are evident. One movement accounts for the North African component of the range of hortensis, while the remaining movements account for subSaharan distributions of lugens, leucomelaena and the boehmi clade (Figure 3). Most divergences in Clade 3 occur in the Miocene and Pliocene; just one divergence is dated in the Pleistocene (Figure 4).

Lineage divergence within Clade 2 began $6.8 \mathrm{Ma}$, prior to the beginning of the MSC at $5.96 \mathrm{Ma}$ (Figure 4). Six subsequent divergences occur in the late Miocene and four occur in the Pliocene (Figure 4). In Clade 2, Island endemics are not each other's closest relatives, indicating multiple vicariance or dispersal events. In this clade, ancestral area reconstructions conflicted depending on how species distributions were coded. If Island distribution was restricted to island endemics (balearica, sarda, melanothorax) and rueppelli (a species with a combined island and very small continental distribution), then continental areas are reconstructed as ancestral for the clade (Figure 3). However, if broadly distributed continental species that also have island distributions are coded as such, then Island is reconstructed as the sole ancestral area for every node in Clade 2 by LaGrange, and for all but two nodes by DIVA (Island + another area; Figure 3). This conflict results in competing interpretations of the biogeographic history of this clade (see below).

\section{Evolution of migration}

Migration is reconstructed as the ancestral state for Sylvia, and as the ancestral state for each of the three major clades (Figure 3). Seven changes in migratory habit are evident but several branches are reconstructed as equivocal under the most parsimonious reconstruction of character state (Figure 3). Using ACCTRAN (change forced to base of tree) to resolve character states at these equivocal nodes suggests that sedentary behavior independently evolved four times, with migratory behavior subsequently evolving three times in two otherwise sedentary clades. Using DELTRAN (change delayed toward tree tips) to resolve character states suggests that migration was lost seven times (no gains; Figure 4). Deciding when to use ACCTRAN or DELTRAN can be problematic [e.g., [53]], but we suggest that assuming more recent evolutionary changes (DELTRAN) in migratory behaviors are consistent with similar studies (both inter-and intraspecific) of other avian lineages which suggest that birds can and do respond rapidly to environmental changes by changing migratory behaviors [e.g., [54]].

\section{Discussion}

\section{Sylvia phylogeny}

Even with long-standing interest in Sylvia systematic relationships, and the use of Sylvia as a model system to explore the evolution of patterns in morphology and range sizes [e.g., $[1,2,6,8,9]]$, the ML phylogeny presented here is the first strongly supported hypothesis of relationships for the genus. Despite this, however, there is topological concordance between our phylogeny and a recent neighbor-joining (NJ) phylogeny used to assess range size in Sylvia [9; BGEA hereafter]. Although the BGEA phylogeny had just 10 of 24 nodes supported at 


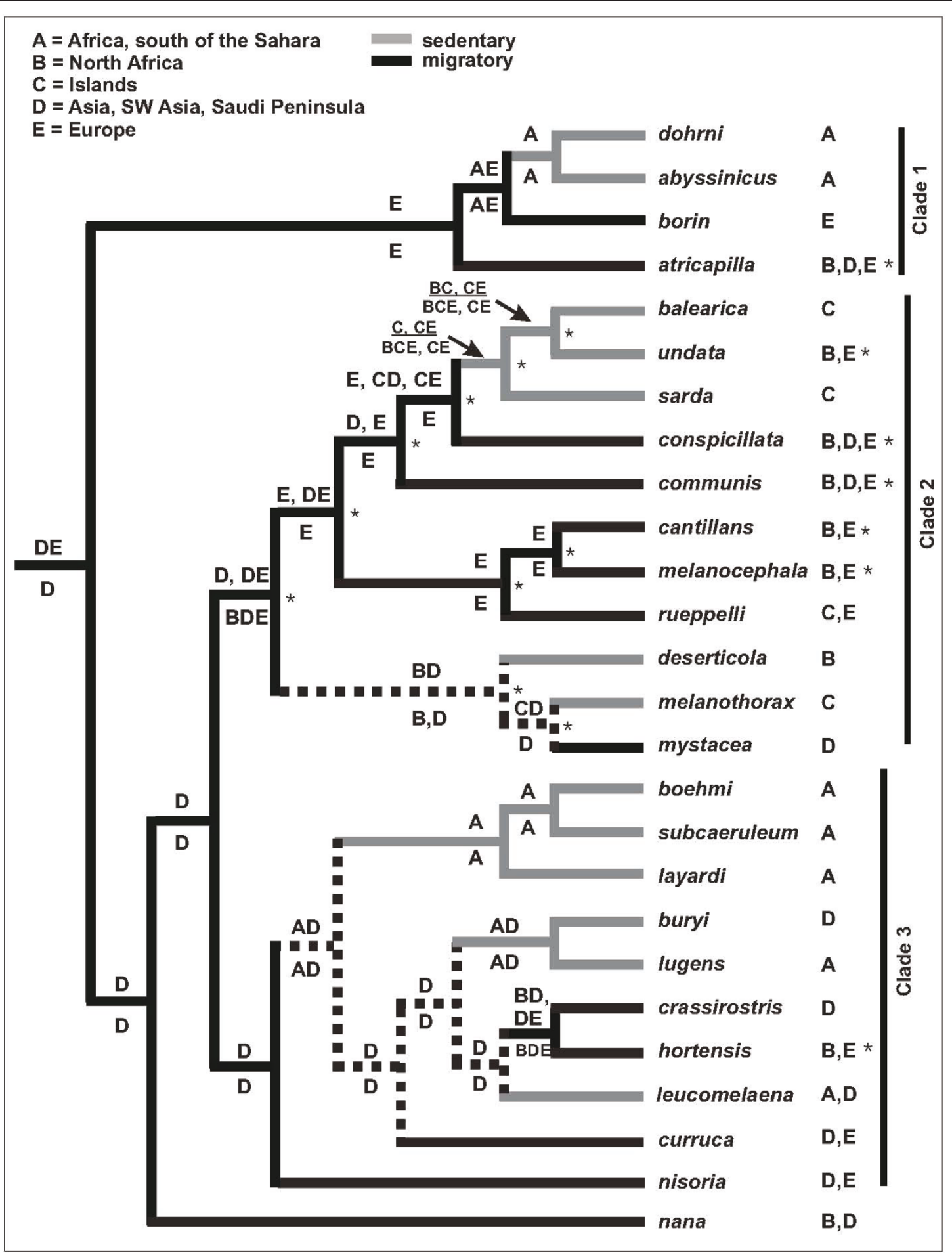

Figure 3 Ancestral area and migratory state reconstructions for Sylvia warblers. Ancestral area reconstructions above nodes are based on DIVA analysis; reconstructions below nodes are based on LaGrange analysis. Asterisks associated with individual species ranges indicate species that have broad continental distributions, but that also have distributions on Mediterranean islands; reconstructions shown above and below nodes do not reflect the inclusion of these island distributions. Alternatively, when Island is included in the distribution of those species and thus is considered as a possible ancestral area, DIVA or LaGrange reconstruct an Island ancestral area at all nodes in one major clade (indicated by asterisks to the right of nodes). Dashed branches indicate equivocal reconstructions under the most parsimonious reconstruction of migratory habit. 


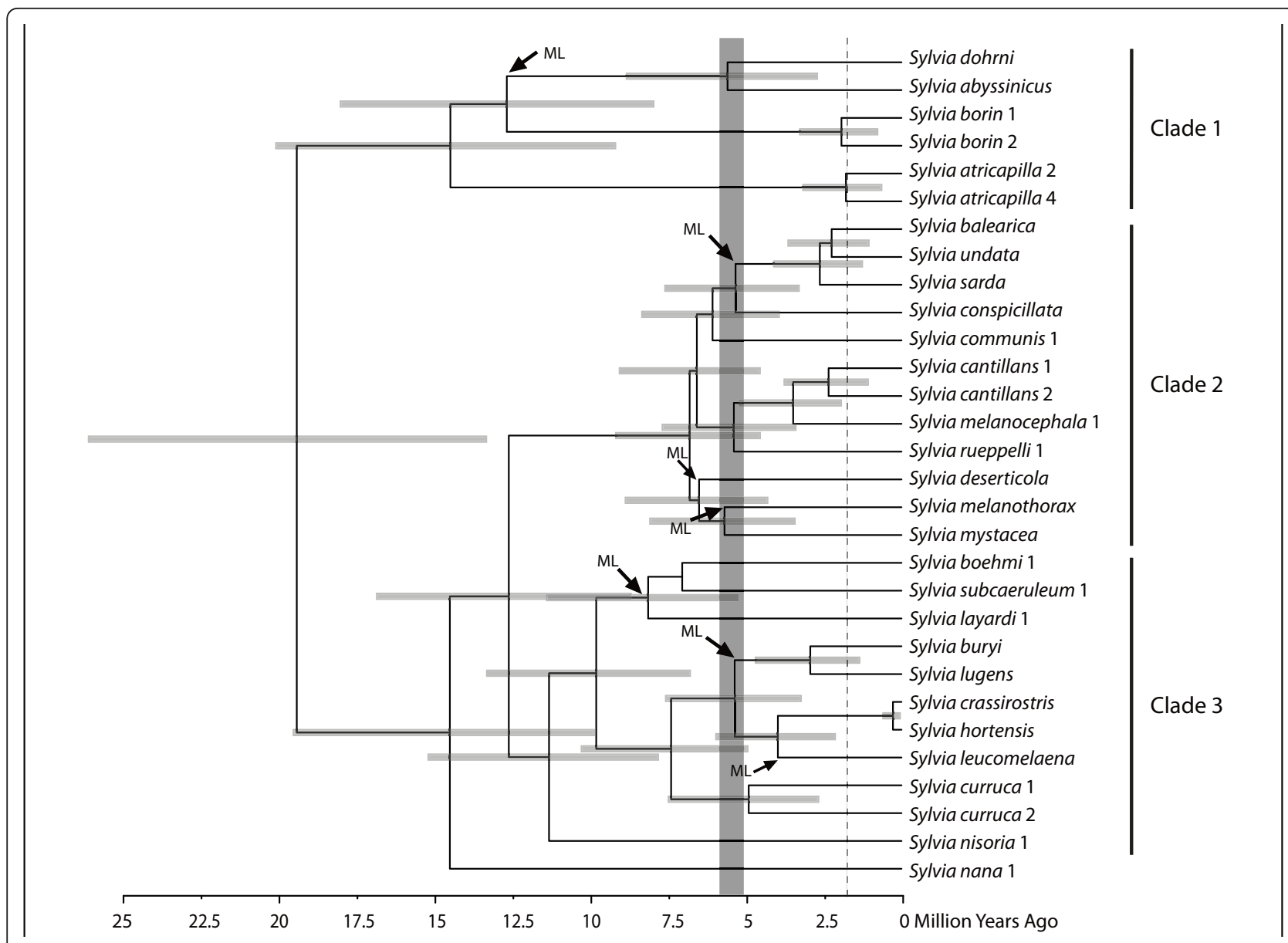

Figure 4 Molecular clock estimates of lineage divergence times in Sylvia, based on a cyt-b mean rate calibration of $2.1 \%$ per million years (see text). Bars at nodes indicate $95 \%$ highest posterior density interval. The vertical shaded rectangle indicates the duration of the Mediterranean Salinity Crisis; the end of the MSC marks the end of the Miocene and the beginning of the Pliocene. The vertical dashed line indicates the Plio-Pleistocene boundary. Arrows with "ML" indicate lineages that have lost long-distance migration.

$>74 \% \mathrm{BS}$, it recovered the three major clades that we recovered in our more exhaustive searches; Sylvia nana was similarly positioned as well.

Intra-clade differences do exist between the BGEA NJ and our ML topologies. Our Clade 1 places S. atricapilla basally and places $S$. borin as sister to other clade members (abyssinica + dohrni), whereas abyssinica occupies the basal position with atricapilla and borin as sisters in BGEA. Our Clade 2 places the deserticola, melanothorax, and mystacea clade as sister to all other clade members, while BGEA places communis as the basal taxon. Our placement of communis renders a "Mediterranean species group" [2,8] polyphyletic. Differences in Clade 2 also include the placement of rueppelli, deserticola, conspicillata, and consequently sister relationship differences are evident as well. Our Clade 3 is topologically congruent with that of BGEA, with the exception of hortensis which BGEA placed basally to crassirostris and leucomelaena. Thus, while there are topological similarities between our phylogeny and that of BGEA (which is itself similar to previous phylogenies based on NJ or DNA-DNA hybridization $[1,2,8]$ ), sufficient differences exist to warrant reassessment of results based on those topologies, all of which were less well supported than our ML phylogeny.

It is possible that nuclear sequence data could provide support for the few nodes that have low support in our phylogeny (Figure 2), or narrow the confidence intervals on our divergence estimates (Figure 4). However, in most avian systematic studies which combine nuclear with mtDNA data or that use nuclear data to test mtDNA results, the nuclear data have not been overly successful at supporting relationships except when species are highly divergent or species-level sampling within a genus is low [e.g. [54,55]]. With respect to divergence dating, studies that examine ways to narrow credibility intervals find that the most important factors affecting divergence time estimation using molecular data are the 
number and distribution of calibration points on the tree [56-59]. These calibrations are primarily fossils, which are generally lacking in number and temporal distribution for most songbird lineages.

\section{Biogeography and lineage diversification: the MSC versus over-water dispersal}

Did the MSC impact speciation in Sylvia, as it has other animal lineages [e.g., [17-24]]? Our divergence dating results suggest that the MSC probably did have an impact, albeit very limited. This is particularly relevant with respect to Clade 2 where most species are distributed around the Mediterranean Sea or on Mediterranean Islands (Figures 3,4). The initial divergences within Clade 2 occur before the beginning of the MSC, with confidence intervals indicating a possibility that diversification could have begun during the MSC. However, these pre-MSC diversifications are not divergences between terminal taxa or between Island versus mainland (or Africa versus Europe) groups. Therefore, we cannot make a convincing argument for population expansion during MSC followed by population fragmentation and isolation as the Mediterranean refilled (i.e., vicariance) as a main driver of speciation in Sylvia.

Consequently, we must instead argue that there has been substantial overwater (trans-Mediterranean) dispersal in Clade 2 since the MSC to explain why many species have Europe + North African distributions (Figure 3). A dispersal argument is supported by the high number of dispersal events inferred by DIVA, and the high number of dispersals can probably be linked to most species with Europe + North African (or broader) distributions being migratory (Figure 3 ).

Further, several Island restricted species (balearica and sarda) clearly achieved their distributions well after the MSC, which suggests over-water dispersals (Figure 4). However, divergence estimates for melanothorax (island endemic) and rueppelli (near island endemic) suggest the possibility that these species achieved their island distributions during the MSC, and became isolated as the Mediterranean refilled at 5.33 Ma (Figure 4). As mentioned above, ancestral area reconstructions and thus biogeographic reconstructions conflict depending on how Island is coded. As such, Islands are either the ancestral distribution for this clade, or they are derived distributions from an Asian ancestral area (Figure 3). While island distributions are typically derived from continental areas [e.g., $[16,28,55]]$, it is clear that islands may also be the source area(s) from which continental distributions are established [e.g., [14,15,28,56]]; migratory behavior is often invoked in the establishment of these distributions.

Post-Miocene divergence dates suggest that Plio-Pleistocene Mediterranean Sea level changes and glacial cycles can also be implicated as factors in driving speciation in Clade 2, where many species have distributions that include Europe (Figure 3). If these factors can be implicated this would suggest that lineage divergence occurred in and between refugial areas [e.g., [34,57-59]]. However, given the extensive range overlap of many closely related species (e.g., rueppelli, melanocephala, cantillans) in Clade 2, we are unable to address this possibility with our data. Phylogeographic studies of European species would be necessary to identify ancestral populations, and to determine whether currently overlapping species were in fact isolated in different refugial areas.

\section{Biogeography and lineage diversification: the role of migration}

It does seem likely that migration played a role in the diversification and distribution of Sylvia, as migratory changes in Clade 2 are consistent with the establishment of all three Island endemic distributions (Figure 3). If Island is the ancestral area for Clade 2, then migratory + Island are the states reconstructed at most basal nodes; subsequently some Island endemics became nonmigratory residents, and continental distribution evolves six times (Figure 3). However, given that migration is the ancestral state for the clade and because no extant Island breeding endemic species has retained long-distance migratory behavior, we feel it more parsimonious to assume that Island endemic distributions in Clade 2 were derived from continental distributions as function of the loss of migration (Figure 3). This then suggests that broadly distributed migratory ancestors' established Island distributions, lost their migratory habit, and were then isolated to become sedentary residents. An exception to this pattern could be melanothorax, which may have lost migration after isolation during the MSC (see above; Figure 3). A loss of long-distance migration is also related to the distribution of deserticola in North Africa, and the Island + mainland (coastal Mediterranean) distribution of undata (Figure 3).

It is less clear how the loss of migration might have played a role in lineage divergence and distribution elsewhere on the phylogeny. In Clade 1, a migratory loss is inferred for the African species dohrni and abysinnicus and is related to their divergence from borin (Figure 3), a Eurasian-breeding species which winters in Africa. This migratory drop-off in Africa suggests a response to ecological change or opportunity, which can clearly play a role in whether migration is gained or lost [e.g., [54,60]]. However, the dohrni-abysinnicus divergence from borin at 12.7 Ma cannot be directly linked to Afro-tropical forest expansion which has been widely implicated in vertebrate speciation in Africa (see below) at ca. $5 \mathrm{Ma}$ [Figure 4; [61-63]]. Neither forest dynamics 
nor change in migratory behavior can explain the divergence between abysinnicus (widespread in Africa) and dohrni [endemic to Príncipe in the Gulf of Guinea; [64]]. This divergence is necessarily explained by an over-water dispersal event by our data here, and the fact that Príncipe is part of the oceanic sector of the volcanic Cameroon Line, and as such has never been connected to mainland Africa [65]. Given the recent discovery that dohrni belongs within Sylvia [3] it is possible that other Sylvia taxa are currently recognized under other genera. One possible example is Lioptilus nigricapillus, which was shown to fall between atricapilla and abysinnicus [but no other Sylvia included; [52]]. Inclusion of Lioptilus in a Bayesian analysis (unpublished data from S. Reddy) indicates a sister relationship with dohrni and abysinnicus (not shown) thereby supporting just a single loss of migration in this clade. Additional "unrecognized" African Sylvia could change both the sister relationship we report for dohrni-abysinnicus, as well as our inference regarding when migration was lost in Clade 1.

In Clade 3, migration was lost three times (Figure 3) and these losses are primarily associated with African taxa. Given that Asia is reconstructed as the ancestral area for this clade, and that migratory behavior is also ancestral, this suggests that these sedentary African lineages are the result of migratory drop-offs (see also below).

\section{Biogeographic and lineage diversification: other factors driving speciation in Sylvia}

It is clear that for species with breeding distributions across Eurasia or that are endemic to Asia or Africa south of the Sahara, factors other than the MSC must be considered to explain lineage divergences. These divergences can include deep intra-specific differences. For example, the divergence between our samples of curruca (dated to 4.9 Ma; Figure 4), could be related to Central Asian aridification peaks which fragmented multiple Eurasian avian lineages through time [66]. This explanation is less likely to explain the deep divergences in either atricapilla or borin, as neither breeds in Eastern Asia [4]. However, divergences in both species are dated near the Plio-Pleistocene boundary (ca. 1.8 Ma; Figure 4), suggesting that European glacial events may have been involved in their divergences. European Pleistocene refugia have been suggested to explain divergences within cantillans [34], although that study did not attempt to date lineage divergences; our results suggest that very late Pliocene events might also have been important for atricapilla and borin. An alternative for the divergence of atricapilla is that disjunct wintering ranges translate to genetically isolated breeding populations. Although wintering range is not fragmented for borin, there is clear evidence that migratory route is under strong genetic control in this species [5,7], and ringing recoveries indicate that breeding populations winter, to some extent, in different areas [4] and are therefore potentially isolated from one another yearround.

At ca. 9.8 Ma Clade 3 diverged in to two sub-clades (Figure 4), one of which is endemic to Africa and is the result of a dispersal event (with migratory loss) from Asia according to ancestral area reconstructions (Figure 3). This clade comprises three arid-adapted species: boehmi is distributed from Ethiopia to Tanzania, while both layardi and subcaeruleum are distributed in southern-most Africa [64]. The timing of movement of this clade from Asia into Africa (Figure 4) was likely facilitated by climate and habitat changes that resulted in an increase in grasses (i.e., more open habitats) in east Africa from 9-5 Ma [see [25,26]], and an inferred movement during this period is consistent with Eurasian to African dispersals by other arid-adapted birds [e.g., $[16,35]]$. Isolation from an Asian ancestor (and a migratory loss) could be explained by tropical forest expansion at $5 \mathrm{Ma}$, which would have served as a vicariance event isolating this clade in southern Africa [e.g., $[16,35]]$.

A second dispersal in this sub-clade, from southern to northeastern Africa, is necessary to explain the distribution of boehmi which diverged from a common ancestor with subcaeruleum $7 \mathrm{Ma}$ (Figure 4). This date seems inconsistent with the general pattern of speciation in arid-adapted species, in that the current range of boehmi spans, both to the north and to the south, the region of eastern Africa where the Afrotropical forest expanded to coastal Kenya. We suggest that prior to establishing its current range, boehmi was either isolated in the north (Ethiopia) from subcaeruleum prior to forest expansion with an extended period for divergence, or that boehmi was isolated in the south (Tanzania). The latter seems more likely given the divergence and palaeo-climatic dates (a phylogeographic study could discriminate between scenarios). A Tanzanian isolation scenario suggests that subcaeruleum and boehmi may have diverged across different arid zone habitats; a similar explanation is necessary to explain their divergence from layardi, whose distribution extensively overlaps that of subcaeruleum [64].

Distributions of the remaining species in Clade 3 involve one dispersal to North Africa + Europe + Islands (hortensis) and two dispersals to Africa (lugens and leucomelaena; Figure 3). The Red Sea is involved in both the distribution of leucomelaena (western and southern Saudi Peninsula + Egypt to Eritrea) and the lugens (Ethiopia to Tanzania) divergence from its common ancestor with buryi (Saudi Peninsula). The Red Sea expanded ca. $7 \mathrm{Ma}$ and seawater had penetrated the 
northern region of the sea by at least $5 \mathrm{Ma}[67,68]$, suggesting that the sea has been a barrier to biotic dispersion since the Miocene-Pliocene boundary. The exception to this is evidence of land-bridges thought to have formed five times during the last 500,000 years, as a result of sea-level lowering during glacial maxima $[69,70]$. The lugens-buryi divergence is dated at $2.9 \mathrm{Ma}$ (Figure 4), suggesting a dispersal event across the Red Sea. This date is consistent with Pliocene tropical forest retraction ca. 3-2.5 Ma ago [61-63], and the concomitant expansion of grassland and desert environments in northeastern Africa [71]. Thus, the lugens-buryi divergence occurred when suitable habitat became available; similar 'suitable habitat' arguments have, when temporally associated with lineage divergences, been used to explain African-Asian interchange in lizards [31], birds $[16,27,28]$ and mammals $[25,26,30]$. Although our single sample does not allow us to discuss the evolution of distribution in S. leucomelaena, additional sampling could reveal whether its trans-Red Sea distribution is the result of over-water dispersal, movement between the Saudi Peninsula and Egypt, or movement across landbridges during the last 500,000 years.

\section{Conclusion}

Our analyses provide the first well-resolved phylogeny for Sylvia warblers, a focal genus for a variety of morphological, behavioral, systematic, and evolutionary studies [e.g., [1,2,5,7-9]]. Molecular clock calibration suggests that Sylvia arose in the early Miocene (19.4 $\mathrm{Ma})$, and that few lineage divergences in the genus were directly driven by palaeo-climatic changes associated with the Messinian Salinity Crisis. Losses of long-distance migratory behavior are correlated with several lineage divergences and distributions, particularly African lineages or Island endemic species. Elsewhere in the phylogeny, divergences can be linked to broad-scale palaeo-climatic events that have been shown to have affected a multitude of vertebrate lineages in both Eurasia [e.g., [66]] and Africa [e.g., [16,26,29,31,35]]. There is evidence that palaeo-climatic changes near the PlioPleistocene boundary may have impacted lineage divergences in Sylvia [34, this study], and additional study is needed to determine if these divergences warrant the recognition of additional Sylvia species.

\footnotetext{
Acknowledgements

We thank the following researchers and museums for the loan of samples used in the study: Katrin Böhning-Gaese, Barrick Museum of Natural History, Moscow State University Zoological Museum, San Diego State University, United States National Museum, University of Washington Burke Museum, Yale Peabody Museum of Natural History, and Zoological Museum University of Copenhagen, and especially Martin Haase for samples from the collection of Andreas Helbig. Laboratory work was supported by NSF DEB-0613668 to GV and R.C.K. Bowie. We thank K. Arnold for her efforts in the lab and two
}

anonymous reviewers for helpful comments for improving the manuscript. This is publication number 1371 of the Texas Cooperative Wildlife Collection and number 191 of the Center for Biosystematics and Biodiversity, both at Texas A\&M University.

\section{Authors' contributions}

GV and JEL contributed equally to study design, analyses and writing of the paper. Both authors read and approved the final manuscript.

Received: 21 December 2010 Accepted: 14 June 2011

Published: 14 June 2011

\section{References}

1. Blondel J, Catzeflis F, Perret P: Molecular phylogeny and the historical biogeography of the warblers of the genus Sylvia (Aves). J Evol Biol 1996, 9:871-891.

2. Böhning-Gaese K, Schuda MD, Helbig AJ: Weak phylogenetic effects on ecological niches of Sylvia warblers. J Evol Biol 2003, 16:956-965.

3. Voelker G, Melo M, Bowie RCK: A Gulf of Guinea island endemic is a member of a Mediterranean-centered bird genus. Ibis 2009, 151:580-583.

4. del Hoyo J, Elliott A, Christie DA: Handbook of the Birds of the World. Vol. 11, Old World Flycatchers to Old World Warblers. Barcelona: Lynx Edicions; 2006

5. Gwinner E, Wiltschko W: Endogenously controlled changes in migratory direction of the Garden Warbler, Sylvia borin. J Comp Physiol 1978, 125:267-273.

6. Leisler B, Winkler H: Ecomorphology. Curr Ornithol 1985, 2:155-186.

7. Gwinner E: Circannual rhythms in bird migration: control of temporal patterns and interactions with photoperiod. In Bird Migration-Physiology and Ecophysiology. Edited by: Gwinner E. New York: Springer-Verlag; 1990:257-268.

8. Shirihai H, Gargallo G, Helbig AJ: Sylvia Warblers. Identification, Taxonomy and Phylogeny of the Genus Sylvia. London: A \& C Black; 2001.

9. Böhning-Gaese K, Caprano T, van Ewijk K, Veith M: Range Size: Disentangling current traits and phylogenetic and biogeographic factors. American Naturalist 2006, 167:555-567.

10. Doswald N, Willis SG, Collingham YC, Pain DJ, Green RE, Huntley B: Potential impacts of climatic change on the breeding and non-breeding ranges and migration distance of European Sylvia warblers. J Biogeogr 2009, 36:1194-1208.

11. Hsü KJ, Montadert L, Bernouilli D, Cita MB, Erikson A, Garrison RE, Kidd RB, Melieres F, Muller C, Wright R: History of the Mediterranean salinity crisis. Nature 1978, 267:399-403.

12. Hsü KJ, Ryan WBF, Cita MB: Late Miocene desiccation of the Mediterranean. Nature 1973, 242:240-244.

13. Krijgsman W, Hilgen FJ, Raffi I, Sierro FJ, Wilson DS: Chronology, causes and progression of the Messinian salinity crisis. Nature 1999, 400:652-655.

14. Filardi CE, Moyle RG: Single origin of a pan-Pacific bird group and upstream colonization of Australasia. Nature 2005, 438:216-219.

15. Voelker G, Rohwer S, Outlaw DC, Bowie RCK: Repeated trans-Atlantic dispersal catalyzed a global songbird radiation. Global Ecology and Biogeography 2009, 18:41-49.

16. Voelker G: Dispersal, vicariance and clocks: Historical biogeography and speciation in a cosmopolitan passerine genus (Anthus: Motacillidae). Evolution 1999, 53:1536-1552.

17. Kodandaramaiah U, Wahlberg N: Phylogeny and biogeography of Coenonympha butterflies (Nymphalidae: Satyrinae) - patterns of colonization in the Holarctic. Syst Entomol 2009, 34:315-323.

18. Reichenbacher B, Kowalke T: Neogene and present-day zoogeography of killifishes (Aphanius and Aphanolebias) in the Mediterranean and Paratethys areas. Palaeogeography, Palaeoclimatology, Palaeoecology 2009, 281:43-56

19. Perea S, Bohme M, Zupancic P, Freyhof J, Sanda R, Ozulug M, Abdoli A, Doadrio I: Phylogenetic relationships and biogeographical patterns in Circum-Mediterranean Subfamily Leuciscinae (Teleostei, Cyprinidae) inferred from both mitochondrial and nuclear data. BMC Evol Biol 2010, $10: 265$.

20. Agustí J, Garcés M, Krijgsman W: Evidence for African-lberian exchanges during the Messinian in the Spanish mammalian record. Palaeogeography, Palaeoclimatology, Palaeoecology 2006, 238:5-14. 
21. Dubey S, Koyasu K, Parapanov R, Ribi M, Hutterer R, Vogel P: Molecular phylogenetics reveals Messinian, Pliocene, and Pleistocene colonizations of islands by North African shrews. Mol Phylogenet Evol 2008, 47:877-882.

22. Fromhage $L$, Vences $M$, Veith $M$ : Testing alternative vicariance scenarios in Western Mediterranean discoglossid frogs. Mol Phylogenet Evol 2004, 31:301-322.

23. Veith M, Mayer C, Samraoui B, Barroso D, Bogaerts S: From Europe to Africa and vice versa: evidence for multiple intercontinental dispersal in ribbed salamanders (Genus Pleurodeles). J Biogeogr 2004, 31:159-171.

24. Kornilios $P$, Kyriazi $P$, Poulakakis $N$, Kumlutaş $Y$, Ilgaz $\otimes$, Mylonas $M$ Lymberakis P: Phylogeography of the ocellated skink Chalcides ocellatus (Squamata, Scincidae), with the use of mtDNA sequences: A hitch-hiker's guide to the Mediterranean. Mol Phylogenet Evol 2010, 54:445-456.

25. Vrba ES: African Bovidae: Evolutionary events since the Miocene. S Afr J Sci 1985, 81:263-266

26. Vrba ES: Mammal evolution in the African Neogene and a new look at the Great American Interchange. In Biological Relationships between Africa and South America. Edited by: Goldblatt P. New Haven: Yale University Press; 1993:393-434.

27. Voelker G: Systematics and historical biogeography of wagtails (Aves: Motacilla): Dispersal versus vicariance revisited. Condor 2002, 104:725-739.

28. Voelker G, Outlaw RK: Establishing a perimeter position: thrush speciation around the Indian Ocean Basin. J Evol Biol 2008, 21:1779-1788.

29. Voelker G, Outlaw RK, Bowie RCK: Pliocene forest dynamics as a primary driver of African bird speciation. Global Ecology and Biogeography 2010, 19:111-121.

30. Montgelard C, Matthee CA, Robinson TJ: Molecular systematics of dormice (Rodentia: Gliridae) and the radiation of Graphiurus in Africa. P Roy Soc B-Biol Sci 2003, 270:1947-1955.

31. Amer SAM, Kumazawa Y: Mitochondrial DNA sequences of the AfroArabian spiny-tailed lizards (genus Uromastyx; family Agamidae): phylogenetic analyses and evolution of gene arrangements. Biol J Linnean Soc 2005, 85:247-260.

32. Sibley CG, Monroe BL Jr: Distribution and Taxonomy of Birds of the World. New Haven: Yale University Press; 1990.

33. Gelang $M$, Cibois A, Pasquet $E$, Olsson U, Alström P, Ericson PGP: Phylogeny of babblers (Aves, Passeriformes): major lineages, family limits and classification. Zool Scr 2009, 38:225-236.

34. Brambilla M, Vitulano S, Spina F, Baccetti N, Gargallo G, Fabbri E, Guidali F, Randi E: A molecular phylogeny of the Sylvia cantillans complex: Cryptic species within the Mediterranean basin. Mol Phylogenet Evol 2008, 48:461-472.

35. Outlaw RK, Voelker G, Outlaw DC: Molecular systematics and historical biogeography of the Rock-Thrushes (Muscicapidae: Monticola). Auk 2007, 124:561-577.

36. Nylander JAA: MrModeltest v2. Program distributed by the author. Evolutionary Biology Centre, Uppsala University; 22004.

37. Huelsenbeck JP, Ronquist F: MRBAYES: Bayesian inference of phylogenetic trees. Bioinformatics 2001, 17(8):754-755.

38. Brandley MC, Schmitz A, Reeder TW: Partitioned Bayesian analyses, partition choice, and the phylogenetic relationships of scincid lizards. Syst Biol 2005, 54(3):373-390.

39. Brown JM, Lemmon AR: The importance of data partitioning and the utility of bayes factors in Bayesian phylogenetics. Syst Biol 2007, 56(4):643-655.

40. Stamatakis AT: RAxML-VI-HPC: maximum likelihood-based phylogenetic analyses with thousands of taxa and mixed models. Bioinformatics 2006 22:2688-2690.

41. Drummond AJ, Ho SYW, Phillips MJ, Rambaut A: Relaxed phylogenetics and dating with confidence. PLoS Biol 2006, 4(5):699-710.

42. Drummond AJ, Rambaut A: BEAST: Bayesian evolutionary analysis by sampling trees. BMC Evol Biol 2007, 7:214.

43. Weir JT, Schluter D: Calibrating the avian molecular clock. Mol Ecol 2008, 17:2321-2328.

44. Nabholz B, Glémin S, Galtier N: The erratic mitochondrial clock: variations of mutation rate, not population size, affect mtDNA diversity across birds and mammals. BMC Evol Biol 2009, 9:54.

45. Fleisher RC, Mclntosh CE, Tarr CL: Evolution on a volcanic conveyer belt: using phylogeographic reconstructions and K-Ar-based ages on the Hawaiian Islands to estimate molecular evolutionary rates. Mol Ecol 1998, 7:533-545
46. Swofford DL: PAUP*. Phylogenetic Analysis Using Parsimony (*and Other Methods). Sunderland, Massachusetts: Sinauer Associates; 42002.

47. Rambaut A, Drummond AJ: TRACER. Oxford: University of Oxford; 2004.

48. Rambaut A: FigTree. 2008 [http://tree.bio.ed.ac.uk/software/figtree/]

49. Ronquist F: Dispersal-vicariance analysis: A new approach to the quantification of historical biogeography. Syst Biol 1997, 46:195-203.

50. Ree RH, Smith SA: Maximum likelihood inference of geographic range evolution by dispersal, local extinction, and cladogenesis. Syst Biol 2008, 57:4-14.

51. Maddison DR, Maddison WP: MacClade. Sunderland, MA, USA: Sinauer Associates; 4.06.0SX 2003.

52. Johansson US, Fjeldså J, Bowie RCK: Phylogenetic relationships within Passerida (Aves: Passeriformes): A review and a new molecular phylogeny based on three nuclear intron markers. Mol Phylogenet Evol 2008, 48:858-876.

53. Agnarsson I, Miller JA: Is ACCTRAN better than DELTRAN? Cladistics 2008, 24:1032-1038.

54. Outlaw DC, Voelker G: Phylogenetic tests of hypotheses for the evolution of avian migration: a case study using the Motacillidae. Auk 2006, 123:455-466.

55. Warren BH, Bermingham E, Prys-Jones RP, Thebaud C: Tracking island colonization history and phenotypic shifts in Indian Ocean bulbuls (Hypsipetes: Pycnonotidae). Biol J Linnean Soc 2005, 85:271-287.

56. Raxworthy CR, Forstner MRJ, Nussbaum RA: Chameleon radiation by oceanic dispersal. Nature 2002, 415:784-787

57. Kasapidis P, Magoulas A, Mylonas M, Zouros E: The phylogeography of the gecko Cyrtopodion kotschyi (Reptilia: Gekkonidae) in the Aegean archipelago. Mol Phylogenet Evol 2005, 35:612-623.

58. Summer RS, Zachos FE: Fossil evidence and phylogeography of temperate species: 'glacial refugia' and post-glacial recolonizatio. J Biogeogr 2009, 36:2013-2020.

59. Vega R, Amori G, Aloise G, Cellini S, Loy A, Searle JB: Genetic and morphological variation in a Mediterranean glacial refugium: evidence from Italian pygmy shrews, Sorex minutus (Mammalia: Soricomorpha). Biol J Linnean Soc 2010, 100:774-787.

60. Cox G: The evolution of avian migration systems between temperate and tropical regions of the New World. American Naturalist 1985, 126:451-474.

61. Hamilton AC, Taylor D: History of climate and forests in tropical Africa during the last 8 million years. Climatic Change 1991, 19:65-78.

62. Feakins SJ, de Menocal PB, Eglinton TI: Biomarker records of late Neogene changes in northeast African vegetation. Geology 2005, 33:977-980.

63. Sepulchre P, Ramstein G, Fluteau F, Schuster M, Tiercelin J-J, Brunet M: Tectonic uplift and eastern African aridification. Science 2006, 313:1419-1423.

64. Sinclair I, Ryan P: Birds of Africa, south of the Sahara. Cape Town: Struik Publishers; 2003

65. Lee D-C, Halliday AN, Fitton JG, Poli G: Isotopic variations with distance and time in the volcanic islands of the Cameroon line: evidence for a mantle plume origin. Earth Plaent Sc Lett 1994, 123:119-138.

66. Voelker G: Repeated vicariance of Eurasian songbird lineages since the late Miocene. J Biogeogr 2010, 37:1251-1261.

67. Girdler RW: The Afro-Arabian rift system. An overview. Tectonophysics 1991, 197:139-153.

68. Ross DA, Schlee J: Shallow structure and geologic development of the southern Red Sea. Geol Soc Am Bull 1973, 84:3827-3843.

69. Rohling EJ, Fenton M, J JF, Bertrand B, Ganssen G, Caulet JP: Magnitudes of sealevel lowstands of the past 500,000 years. Nature 1998, 394:162-164.

70. Siddall M, J RE, Almogi-Labin A, Hemleben C, Meischner D, Schmelzer I, Smeed DA: Sea-level fluctuations during the last glacial cycle. Nature 2003, 423:853-858.

71. McClanahan TR, Young TP: East African ecosystems and their conservation. Oxford: Oxford University Press; 1996.

doi:10.1186/1471-2148-11-163

Cite this article as: Voelker and Light: Palaeoclimatic events, dispersal and migratory losses along the Afro-European axis as drivers of biogeographic distribution in Sylvia warblers. BMC Evolutionary Biology 2011 11:163. 